\title{
Islam Nusantara: Strategi Perjuangan "Keumatan" Nahdlatul Ulama
}

\author{
Ahmad Khoirul Mustamir \\ Program Pascasarjana Institut Agama Islam Tribakti Kediri \\ mustamir09@gmail.com
}

\begin{abstract}
The Islamic Discourse of the Archipelago increasingly found its momentum in the struggle for the meaning of Islam. Many are pros and not a few cons. The pros, driven by the NU religious movement. While those who are cons, radical groups are identified. In this context, it is important to study more deeply about Islam Nusantara. This research uses the method of library research or Library Research. A literature study is a data collection technique by conducting a study of books, literature, notes, and reports that are related to the problem being solved. This article utilizes journals, materials and relevant information to be collected, read and reviewed, recorded as a guide or reference source. The results showed that the ability of Islamic da'wah to adapt to local culture made it easier for Islamic da'wah to enter the lowest strata of society. Inevitably, Islam as a religion that spreads throughout the world appears creatively in dialogue with the local community (local), is in a position to accept the traditions of the community, while modifying it into a new culture that can be accepted by the local community and still within the path of Islam. Therefore, the arrival of Islamic da'wah is enlightenment for the Southeast Asian region, especially Indonesia.
\end{abstract}

Keywords: Islam Nusantara, Struggle Strategy, Nahdlatul Ulama

\begin{abstract}
Abstrak
Wacana Islam Nusantara semakin menemukan momentumnya dalam perebutan makna Islam. Banyak yang pro dan tidak sedikit yang kontra. Yang pro, dimotori oleh gerakan keagamaan NU. Sedangkan yang kontra, teridentifikasi kelompok-kelompok radikal. Dalam konteks inilah, penting untuk mengkaji lebih mendalam tentang Islam Nusantar. Penelitian ini menggunakan metode studi kepustakaan atau Library Research. Studi kepustakaan adalah teknik pengumpulan data dengan mengadakan studi penelaahan terhadap buku-buku, literatur-literatur, catatan-catatan, dan laporan-laporan yang ada hubungannya dengan masalah yang dipecahkan. Artikel ini memanfaatkan jurnal, bahan-bahan dan informasi yang relevan untuk dikumpulkan, dibaca dan dikaji, dicatat sebagai pedoman ataupun sumber referensi. Hasil penelitian menunjukkan, kemampuan dakwah Islam untuk beradaptasi dengan budaya setempat, memudahkan dakwah Islam masuk ke lapisan paling bawah dari masyarakat. Tak pelak lagi, Islam sebagai agama yang menyebar ke seluruh penjuru dunia tampil secara kreatif berdialog dengan masyarakat setempat (lokal), berada dalam posisi yang
\end{abstract}


menerima tradisi masyarakat, sekaligus memodifikasinya menjadi budaya baru yang dapat diterima oleh masyarakat setempat dan masih berada di dalam jalur Islam. Karena itu, kedatangan dakwah Islam merupakan pencerahan bagi kawasan Asia Tenggara, khususnya Indonesia.

Kata Kunci: Islam Nusantara, Strategi Perjuangan

\section{Pendahuluan}

Wacana Islam Nusantara semakin menemukan momentumnya dalam perebutan makna Islam. Jika dilihat kebelakang, wacana ini mengeras saat dijadikan tema pada Muktamar NU ke-33 di Jombang, Jawa Timur, pada 1-5 Agustus 2015. Tema "Meneguhkan Islam Nusantara untuk Peradaban Indonesia dan Dunia" sepertinya menjadi lompatan besar NU dalam penegasan kongkretisasi nilai-nilai Islam Nusantara yang secara normatif doktrinal menganut ajaran Islam ahlussunnah wal jamaah an nahdliyah. ${ }^{1}$ Diskursus inipun dijadakan sarana dakwah keuamatan dalam membendung faham radikalisme.

Menurut Azyumardi Azra “Islam Nusantara" dalam dunia akademis mengacu kepada "Southeast Asian Islam" yang terdapat di wilayah Muslim Indonesia, Malaysia, Brunei, Pattani (Thailand Selatan) dan Mindanau (Filipina Selatan). Wilayah Islam Nusantara dalam literatur prakolonial disebut "negeri bawah angin" (lands below the wind). Lebih spesifik dalam literatur Arab sejak abad ke-16, kawasan Islam Nusantara disebut "bilad al-Jawi" (Negeri Muslim Jawi), yaitu Asia Tenggara. Umat Muslimin Nusantara biasa disebut

1 M. Ramlan, Tata Bahasa Indonesia: Penggolongan Kata (Yogyakarta: Andi Offset, 1985). H. 37 sebagai "ashab al-Jawiyyin" atau "jama'ah al-Jawiyyin". ${ }^{2}$

Dalam konteks ini, Islam Nusantara mirip dengan karakter Islam dalam tujuh ranah agama dan budaya. Perspektif religio-cultural Islam Islam Nusantara seperti Islam Arab, Islam Persia/Iran, Islam Turki, Islam Anak Benua India, Islam Sino Islamic, Islam Afrika Hitam dan Islam Dunia Barat. Kedelapan religio cultural tersebut, mempunyai persamaan dalam bidang akidah dan ibadah, akan tetapi memiliki ranah karakter keagamaan berdasarkan budaya sendiri-sendiri. Islam dan budaya akan menemukan prinsip yang saya tentang nilai-nilai kemanusiaan universal (persamaan, keadilan, perdamaian, penghormatan, toleransi dan lain sebagainya.

Akhmad Sahal menuturkan, pemahaman mengenai Islam Nusantara mensyaratkan adanya hubungan yang saling terkait antara dimensi keagamaan dan budaya. Dimensi ini menjadikan Islam mampu berdialektika dengan batas wilayah geografis teritorial yang memiliki akar budaya tertentu. Dengan demikian, Islam tidak lagi menampilkan wajah suram, kaku dan tertutup, namun lebih menghargai perbedaan, membiar-

2 Azyumardi Azra, "Islam Indonesia Berkelanjutan", dalam Opini Kompas, 3 Agustus 2015. 
kan yang lain hadir dalam ruang sosial dan budaya. Islam, dalam kapasitas demikian, sangat mengakomodir nilainilai sosial dan budaya yang sudah berlangsung selama berabad-abad dalam suatu wilayah tertentu. Hal ini ditegaskan pula oleh Abdurrahman Wahid (Gus Dur), yang mengatakan, "Tumpang tindih antara agama dan budaya akan terjadi terus menerus sebagai suatu proses yang akan memperkaya kehidupan dan membuatnya tidak gersang." 3

Pandangan ini sekaligus menegaskan, Islam Nusantara menolak cara-cara beragama yang diekspresikan oleh kelompok Islamisme atau kelompok radikal. Kelompok-kelompok ini menolak Islam Nusantara, karena Islam Nusantara diangap sebagai madzhab baru. mereka berpendapat, madzhab baru ini tidak mempunyai landasan secara historis ataupun nasab keilmuan kepada madzhab-madzhab yang sudah diakui dalam keilmuan keIslaman. Pandangan ini pun mendaoatkan respon dari KH. Mustofa Bisri (Gus Mus).

Menurut KH. Mustofa Bisri (Gus Mus) kata Nusantara itu akan salah maksud jika dipahami dalam struktur na'at-man'ut (penyifatan) sehingga berarti, "Islam yang dinusantarakan." Akan tetapi akan benar bila diletakkan dalam struktur idhafah (penunjukan tempat) sehingga berarti "Islam di

Nusantara". ${ }^{4}$ Menurut ulama-ulama dan cendekiawan NU, penjelasan Gus Mus di atas memang tidak salah dalam konteks untuk meredam ketakutan-ketakutan suatu kelompok tertentu yang salah dalam memahami Islam Nusantara. Namun perlu dipahami bahwa penunjukan tempat juga berarti menguak unsur-unsur yang ada dalam tempat tersebut. Maka, mau tidak mau, suka atau tidak suka, kita harus tetap merangkul watak dan karakteristik dari sebuah wilayah yang bernama Nusantara.

Ulasan secara akademik, seperti yang disampaikan Teuku Kemal Fasya dalam esainya, Dimensi Puitis dan Kultural Islam Nusantara, Ia mendefinisikan bahwa Islam Nusantara ialah proses penghayatan dan pengamalan lokalitas umat yang tinggal di Nusantara. Penabalan kata "Nusantara" bukan sekadar penegasan nama tempat atau nomina, melainkan lebih penting, penjelasan adjektiva atau kualitas Islam "di sini" yang berbeda dengan Islam "di sana". Keberhasilan Islam jadi agama Nusantara yang damai tak bisa dilepaskan dari daya adaptasi dan resiliensi pengetahuan, kesenian dan kebudayaan lokal. Kredo teologis yang serba melangit itu bertemu dengan dimensi kultural masyarakat dan beresonansi melalui pengetahuan lokal. ${ }^{5}$ Hal ini menemukan bentuk hitorisnya (a)

${ }^{3}$ Akhmad Sahal (eds.), Islam Nusantara Dari Ushul Figh hingga Paham Kebangsaan, Cet. I (Bandung: Mizan Pustaka, 2015), h. 33.

4 Edi AH Iyubenu, "Ontran-Ontran Islam Nusantara", dalam Opini Jawa Pos, 24 Juli 2015.

5 Teuku Kemal Fasya, "Dimensi Puitis dan Kultural Islam Nusantara", dalam Opini Kompas, 4 Agustus 2015. 
dalam sejarah penyebaran Islam yang dilakukan oleh wali songo.

Lepas dari beragam istilah yang muncul untuk menunjuk kepada Islam Nusantara yang memiliki beragam konsekuensi terminologis. Namun demikian, dapat dipastikan secara kultural Islam Nusantara yang di dalamnya melekat pelbagai sistem nilai masih terasa pengaruhnya dalam perkembangan Islam di Indonesia hingga saat ini. Benih-benih Islam Nusantara selama berabad-abad sudah tersemaikan di negeri ini dan memberi perangkat fungsional yang memberi warna keislaman kepada kehidupan bangsa secara keseluruhan.

Dengan demikian, khazanah Islam Nusantara yang menjadi blueprint (cetak biru) karena 'terlembagakan' dalam pelbagai sistem kepercayaan atau tradisi keagamaan NU tidak dapat dipisahkan dari proses dakwah atau penyebaran Islam di Indonesia sejak beberapa abad sebelumnya. ${ }^{6}$ Dalam kapasitas demikian, NU telah berupaya 'mengislamkan' nilainilai ke-Nusantara-an dan 'menusantarakan' nilai-nilai ke-Islam-an, setidaknya melalui tiga doktrin ortodoksi. Ketiga ortodoksi itu adalah Pertama, dalam bidang teologi, NU menganut faham Asyáriyah dan Maturidiyah. Kedua dalam bidang fiqih, NU mengikuti empat madzhab, yaitu Hanafi, Maliki, Syafi'í, dan Hambali. Ketiga dalam bidang tasawuf, NU menganut pemikiran Imam Junaid al-Baghdadi dan Imam al-Ghazali.
Melalui ketiga doktrin ortodoksi inilah, NU telah berhasil memunculkan wajah Islam-yaitu Islam Nusantara-yang berbeda dengan Islam di pelbagai belahan dunia.

Pandangan terssebut menjadai cara pandang pemikiran Institut Agama Islam Tribakti (IAIT) Kediri. Perspektif ini menjadi ruh ke-Islam-an yang ditranformasikan ke dalam kehidupan seluruh civitas akademis IAIT Kediri. Meskipun demikian, IAIT sangat menghormati cara pandang berbeda tentang Islam Nusantara di lingkungan akademis. Perbedaan ini justru akan membangun dan mengenbangkan dinamika pemikiran dan keilmuan Islam di lingkup IAIT Kediri.

Berdasarkan hal itu, penulis akan membatasi tema tulisan ini dalam konteks pro terhadap Islam Nusantara. Bagi yang menolak, penulis memohon untuk menuliskan gagasannya melalui karya tulis Ilmiah sebagai bentuk kedewasaan intelaktual. Akhirnya, dalam pendangan penulis, karya yang sudah dipublis, maka tafsir makna bukan milik penulis akan tetapi milik publik. Bahasan penelitian ini dibatasi dalam menyoal Islam Nusantara dalam Ideologi dan Tradisi, serta Islam Nusantara dalam lanskap pribumisasi Islam.

\section{Metode}

Penelitian ini menggunakan metode studi kepustakaan atau Library Research. Studi kepustakaan adalah 
teknik pengumpulan data dengan mengadakan studi penelaahan terhadap buku-buku, literatur-literatur, catatancatatan, dan laporan-laporan yang ada hubungannya dengan masalah yang dipecahkan. Artikel ini memanfaatkan jurnal, bahan-bahan dan informasi yang relevan untuk dikumpulkan, dibaca dan dikaji, dicatat sebagai pedoman ataupun sumber referensi. Metode studi pustaka dalam artikel ini dapat dijadikan sebagai data dan sumber data mengenai topik masalah. Library Research ini bertujuan untuk memberikan gambaran kepada pembaca, tentang topik masalah yang sedang diteliti.

\section{Hasil dan Pembahasan}

Seperti disinggung di awal, Islam Nusantara adalah Islam khas Indonesia yang mengutamakan toleransi, menerima perbedaan, baik agama, suku, ras, maupun budaya. Dengan demikian, doktrin Islam Nusantara menjadi palang pintu pertama dalam membangun kebersamaan melalui nilai-nilai inklusif seperti tawasuth (moderat), tasamuh (toleransi), tawazun (tolong menolong), tawazun (harmoni), dan lain-lain. Pemahaman ini, jelas sebagai penjelas identifikasi terhadap akar nilai-nilai inklusif tersebut telah menghunjam di dasar kesadaran mayoritas umat Islam di Indonesia. Ekspresi keagamaan muslim Indonesia syarat melekat kuat di dalamnya, aspek budaya, tradisi dan adat istiadat.
Berbeda dengan pandangan keagamaan Islam eksklusif. Islam eklusifisme menjadikan pemahaman keagamaan kearah radikal. Secara sederhana radikalisme adalah pemikiran atau sikap yang ditandai oleh empat hal yang sekaligus menjadi karakteristiknya, yaitu: pertama, sikap tidak toleran dan tidak mau menghargai pendapat atau keyakinan orang lain. Kedua, sikap fanatik, yaitu selalu merasa benar sendiri dan menganggap orang lain salah. Ketiga, sikap eksklusif, yaitu membedakan diri dari kebiasaan orang kebanyakan. Keempat, sikap revolusioner, yaitu cenderung menggunakan kekerasan untuk mencapai tujuan. ${ }^{7}$

Dalam konteks Indonesia, kondisi Kehidupan keagamaan umat Islam pada saat ini tidak dapat dipisahkan dari proses dakwah atau penyebaran Islam sejak beberapa abad sebelumnya. Ketika Islam masuk di Indonesia, kebudayaan Nusantara telah dipengaruhi oleh agamaagama yang telah datang sebelumnya, seperti Hindu dan Budha, termasuk pelbagai kepercayaan tradisional, sebut saja animisme, dinamisme, (mohon maaf, aliran kepercayaan dalam konteks sekarang) dan sebagainya. Kebudayaan Islam akhirnya menjadi tradisi kecil di tengah pusaran tradisi Hinduisme dan Budhisme. Tradisi-tradisi kecil inilah

${ }^{7}$ Agil asshofie, Radikalisme Gerakan Islam, alisme-gerakan-politik.html, diakses pada 10 Desember 2019. 
yang kemudian saling mempengaruhi dan mempertahankan eksistensinya. ${ }^{8}$

Dalam sejarahnya, Nusantara yang pertama dan menjadi bidikan penyebaran Islam adalah pusat-pusat perdagangan yang ada di wilayah perkotaan di daerah pesisir. Sementara Islam ortodok dapat masuk secara mendalam di wilayah luar Jawa yang memang tidak banyak terpengaruh oleh nilai-nilai dan tradisi-tradisi baik itu dari Hindu atau Budha. Berbeda dengan di Jawa. Di wilayah ini, agama Islam menghadapi resistensi dari Hinduisme dan Budhisme yang telah mapan. Dalam proses seperti ini, Islam tidak saja harus menjinakkan sasarannya, tapi juga harus memperjinak diri. ${ }^{9}$ Benturan dan resistensi dengan kebudayaan-kebudayaan setempat memaksa Islam untuk mendapatkan simbol yang selaras dengan kemampuan penangkapan kultural dari masyarakat setempat.

Kemampuan Islam untuk beradaptasi dengan budaya setempat, memudahkan Islam masuk ke lapisan paling bawah dari masyarakat. Akibatnya, kebudayaan Islam sangat dipengaruhi oleh kebudayaan petani dan kebudayaan pedalaman, sehingga

8 George W. Braswell, Islam: Its Prophet, Peoples, Politics and Power (Nashville: Broadman \& Holman Publishers, 1996). Lihat juga Arbiyah Lubis, Pemikiran Muhammadiyah dan Muhammad Abduh, Suatu studi Perbandingan, (Jakarta: Bulan Bintang, 1993); Hamid Algadari, Dutch Policy Against Islam and Indonesian of Arab Descent in Indonesia (Jakarta: LP3ES, 1994), 21; Arohman Prayitno, Trubus Rahardiansyah P., Ethics for a Multicultural Society: Strategic Solutions ㄱ for Interweaving Togetherness the Frame Work of m Pluralism (Jakarta: Trisakti University Press, 2008), h. 67 . kebudayaan Islam mengalami transformasi bukan saja karena jarak geografis antara Arab dan Indonesia, tetapi juga karena ada jarak-jarak kultural. ${ }^{10}$ Proses kompromi kebudayaan seperti ini tentu membawa resiko yang tidak sedikit, karena dalam keadaan tertentu seringkali bersikap toleran terhadap penafsiran yang mungkin dianggap menyimpang dari ajaran Islam yang murni. Kompromi kebudayaan ini pada akhirnya melahirkan, apa yang di pulau Jawa dikenal sebagai sinkretisme atau Islam Abangan. Sementara di pulau Lombok dikenal dengan istilah Islam Wetu Telu. ${ }^{11}$

Proses islamisasi yang berlangsung di Nusantara tidak terlepas dari proses akulturasi. Seperti telah diketahui bahwa Islam disebarkan ke Nusantara sebagai kaedah normatif di samping aspek seni budaya. Sementara itu, masyarakat dan budaya di mana Islam itu disosialisasikan adalah sebuah alam empiris. Dalam konteks ini, sebagai makhluk berakal, manusia pada dasarnya beragama dan dengan akalnya pula mereka paling mengetahui dunianya sendiri. Pada alur logika inilah manusia, melalui perilaku budayanya senantiasa meningkatkan aktualisasi diri. Karena

9 Taufik Abdullah, Taufik, "Pengantar: Islam, Sejarah dan Masyarakat", dalam Taufik Abdullah [ed.], Sejarah dan Masyarakat:Lintasan Historis Islam di Indoensia, (Jakarta: Pustaka Firdaus, 1987), h. 3.

10 Hildred Geertz, "Indonesian Cultures and Communities," in Indonesia, ed. Ruth T. McVey (New Haven, CT: Human Relations Area Files, 1963), h. 6.

11 Lihat Muhammad Harfin Zuhdi, Parokialitas Adat terhadap Pola Keberagamaan Komunitas Islam Wetu Telu di Bayan Lombok (Jakarta: Lemlit UIN Jakarta, 2009), h. 111. 
itu, dalam setiap akulturasi budaya, manusia membentuk, memanfaatkan, mengubah hal-hal paling sesuai dengan kebutuhannya.

Dari paradigma inilah, masih dalam kerangka akulturasi, lahir apa yang kemudian apa yang dikenal sebagai local genius. Di sini local genius bisa diartikan sebagai kemampuan menyerap sambil mengadakan seleksi dan pengolahan aktif terhadap pengaruh kebudayaan asing, sehingga dapat dicapai suatu ciptaan baru yang unik, yang tidak terdapat di wilayah bangsa yang membawa pengaruh budayanya. ${ }^{12}$ Pada sisi lain, secara implisit local genius dapat dirinci karakteristiknya, yakni: mampu bertahan terhadap dunia luar; mempunyai kemamapuan megakomodasi unsur-unsur dunia luar; mempunyai kemampuan mengintegrasi unsur budaya luar ke dalam budaya asli; dan memiliki kemampuan mengendalikan dan memberikan arah pada perkembangan budaya selanjutnya. ${ }^{13}$

\section{Kembali kepada Ideologi dan Tradisi}

Islam Nusantara yang seolah menjadi garis kesadaran sejarah dapat dilihat dengan jelas dalam kiprah NU sebagai ormas terbesar di negeri ini. Dalam kapasitas ini, NU sangat jenius mendialogkan ajaran-ajaran agama yang bertumpu, setidaknya dari tiga aspek,

${ }^{12}$ Harry Parkin, Batak Fruit of Hindu Thought (India: Christian Literature Society, 1978), h. 28

13 Soerjanto Poespowardojo, "Pengertian Local Genius dan Relevansinya dalam Modernisasi" dalam Kepribadian Budaya Bangsa (local genius), Ayotrohaedi (ed.) (Jakarta: Pustaka Jaya, 1986), h. 28-38. yaitu aspek doktrinal normatif, historis dan budaya. Karena itu, para ulama NU dengan piawai mampu menyemaikan benih-benih ajaran Islam ahlussunnah wal jamaah an nahdliyah dengan cara damai dan santun dalam setiap perjumpaannya dengan beragam budaya, tradisi dan adat-istiadat yang diwarisi dari pola dakwah Walisongo. Dalam konteks inilah, diperlukan proses reideologisasi dan retradisionalisasi Islam Nusantara dalam bentuknya yang sangat kultural. Artinya, nilai-nilai Islam yang telah lama menjiwai kehidupan umat Islam di Indonesia misalnya, dicoba dihidupkan kembali secara bulat dan utuh. Dari sinilah maka kerangka ideologis adalah suatu keniscayaan. Tentu ideologi yang dimaksudkan di sini bukan ideologi politik, melainkan ideologi kultural, seperti desakan untuk menciptakan dalam bahasa Gus Dur (Abdurrahman Wahid) masyarakat Islam yang 'tuntas', yang di dalamnya nilai-nilai Islam berkembang secara penuh tanpa penyimpangan atau distorsi apapun. ${ }^{14}$ Dengan demikian, proses yang seperti ini juga memunculkan retradisionalisasinya sendiri, yaitu ketika tradisi masa lalu direkatkan dan dikaitkan satu sama lain dengan sebuah kerangka tradisi yang utuh, antara tradisi dan ideologi, walaupun hanya ideologi kultural, lalu

${ }^{14}$ Abdurrahman Wahid, Islam Kosmopolitan: Nilai-Nilai Indonesia dan Transformasi Kebudayaan, (Jakarta: The Wahid Institute, 2007), h. 193. A. Jauhar Fuad, "Tlatah Dan Tradisi Keagamaan Islam Mataraman," Jurnal Pemikiran Keislaman 30, no. 1 (January 31, 2019): 1-27, https://doi.org/10.33367/tribakti.v30i1.659 
terjadi kaitan simbiosis untuk saling mendukung dan saling menguatkan.

Wajah keberagamaan di Indonesia justru menemui kematangannya karena telah bersalin rupa dalam paras Nusantara. Islam Nusantara adalah wujud kematangan yang terrefleksikan dari ajaran-ajaran Islam universal. Secara empiris, ia terbukti bisa bertahan dalam sekian banyak kebudayaan non-Arab. Ia bahkan ikut menciptakan ruang-ruang kebudayaan yang sampai hari ini ikut dihuni oleh mereka yang non-muslim sekalipun. ${ }^{15}$

Dalam konteks ini, budaya atau kebudayaan adalah bersifat spesifik manusiawi. Artinya, manifestasi dan perwujudan dari segala aktivitas manusia sebagai upaya untuk memudahkan dan memenuhi kebutuhan hidupnya. Kebudayaan terdiri dari nilai dan simbol. ${ }^{16}$ Nilai-nilai budaya itu tidak kasat mata, sedangkan simbol budaya yang merupakan perwujudan nilai itulah yang kasat mata. Pelbagai bentuk simbol budaya, seperti masjid, pasar, sekolah, rumah misalnya adalah perwujudan dari nilai-nilai budaya masyarakatnya. Dalam setiap aktivitas manusia, nilai-nilai budaya senantiasa hadir dan melekat di dalamnya sistem nilai, yaitu nilai budaya, meski terkadang tidak serta merta merupakan simbol budaya.

Dalam konteks ini pula, manusia mampu mengetahuinya melalui pola

15 A. Musthofa Haroen, Meneguhkan Islam Nusantara: Biografi Pemikiran dan Kebangsaan Prof. ๖ Dr, KH. Said Aqil Siroj, MA (Jakarta: Khalista 2015), h.121. persemaian nilai-nilai luhur Islam Nusantara, setidaknya dengan dakwah (propagation) dalam segala bentuknya. ${ }^{17}$ Dakwah tidak lain adalah seruan bagi umat manusia menuju jalan Tuhan, yaitu jalan menuju Islam. Islam yang bersumber dari wahyu Tuhan dan sunnah Rasul-Nya, adalah sumber nilai yang akan memberikan corak, warna dan bentuk kebudayaan Islam. Suatu bentuk kebudayaan yang berisikan pesan atau nilai-nilai Islami, boleh jadi muncul dari orang atau masyarakat di luar Islam. Demikian juga sebaliknya, tidak dikatakan budaya Islam, walau ia lahir dari orang atau masyarakat yang menganut ajaranIslam, jika tidak memuat pesan atau nilai-nilai Islami. Sebagai aktualisasi imani (teologis), dakwah Islam teraktualisasikan dalam pelbagai sistem kegiatan sosial kemasyarakatan, setidaknya untuk mempengaruhi warga masyarakat dalam upaya untuk merealisasikan ajaran Islam dalam semua segi kehidupan dengan menggunakan cara tertentu.

Dalam perspektif ini, budaya atau kebudayaan adalah aktualisasi dari sikap tunduk manusia kepada Tuhan. Sebagaimana dalam Al-Qur'an yang artinya: "Dan penyair-penyair itu diikuti oleh orang-orang yang sesat. Tidakkah kamu melihat bahwasanya mereka mengembara di tiap-tiap lembah, dan bahwasanya mereka suka mengatakan apa yang mereka sendiri tidak mengerjakan (nya)?, kecuali orang-

${ }^{16}$ Lihat F Allan Hanson, Meaning in Culture (London and New York: Routledge, 2004), h.99100.

${ }_{17}$ Majma' al-Lughah al-'arabiyah (Beirut: Dar al-Fikr, 1972), h. 286. 
orang (penyair-penyair) yang beriman dan beramal saleh dan banyak menyebut Allah dan mendapat kemenangan sesudah menderita kezaliman. Dan orang-orang yang zalim itu kelak akan mengetahui ke tempat mana mereka akan kembali". ${ }^{18}$

Ayat di atas menginformasikan bahwa ada dua jenis budaya yang diwakili oleh sosok pelakunya. Pertama, budaya yang dibangun dengan dimensi taqwa yang diwakili oleh sosok pelaku budaya yang beriman, beramal shaleh, dan senantiasa berdzikir mengingat Allah serta sabar menghadapi kezaliman. Jika disepakati bahwa budaya itu spesifik manusiawi, maka pengaruh ideologi, pandangan hidup, sikap hidup, dan cara berpikir pelaku atau peletek budaya itu menjadi nilai dasar dari bentuk budaya tersebut. Dengan demikian, seseorang yang memiliki kesalehan individual dan kesalehan sosial dalam dirinya, tentu akan melahirkan jenis budaya yang juga beroreintasi memudahkan jalan orang lain atau masyarakat untuk menjadi shaleh (al-Khair al-Ummah). Kedua, budaya yang dibangun dengan dimensi kesesatan dan kezhaliman. Seseorang yang berlatar belakang ideologi komunis atau kapitalis, misalnya, tentu juga akan menampilkan bentuk budaya dengan orientasi dan cara berpikir ideologi dimaksud dalam membangun tatanan masyarakatnya.

18 (Q.S.Asy-Syua'ara [26]: 224-227).

19 Bassas Tibbi, Islam and Cultutral Accommodation of Social Change (San Francisco: Westview Pres, 1991), 1. Lihat juga Mary-Paula Walsh, Feminism and Christian Tradition: An Annotated Bibliography and Critical Introduction to
Selanjutnya berkaitan dengan relasi antara Islam sebagai agama dengan budaya lokal sangat jelas dalam kajian antropologi agama. Dalam perspektif ini diyakini bahwa agama merupakan penjelmaan dari sistem budaya. ${ }^{19}$ Berdasarkan teori ini, Islam sebagai agama samawi dianggap penjelmaan dari sistem budaya suatu masyarakat Muslim. Tesis ini kemudian dikembangkan pada aspek-aspek ajaran Islam, termasuk aspek hukumnya. Para pakar antropologi dan sosiologi mendekati hukum Islam sebagai sebuah institusi kebudayaan Muslim. Pada konteks sekarang, pengkajian hukum dengan pendekatan sosiologis dan antrologis sudah dikembangkan oleh para ahli hukum Islam yang peduli terhadap nasib syari'ah. Dalam pandangan mereka, jika syari'ah hanya didekati secara doktrinal tidak didekati secara sosio-historis, maka yang terjadi adalah pembakuan terhadap norma syariah yang sejatinya bersifat dinamis dan mengakomodasi perubahan masyarakat. ${ }^{20}$

Islam sebagai agama, kebudayaan dan peradaban besar dunia sudah sejak awal masuk ke Indonesia pada abad ke-7 dan terus berkembang hingga kini. Ia telah memberi sumbangsih terhadap keanekaragaman kebudayaan Nusantara. Islam tidak saja hadir dalam tradisi agung [great tradition] bahkan memperkaya pluralitas dengan islamisasi kebudayaan

the Literature (London, Greenwood Press, 1999), h.127

${ }^{20}$ Muhammad Harfin Zuhdi, "Dakwah dan Dialektika Akulturasi Budaya", dalam Religia, jurnal Ilmu-Ilmu Keislaman, Vol. 15, No. 1, April, 2012, h.18 
dan pribumisasi Islam yang pada gilirannya banyak melahirkan tradisitardisi kecil (little tradition) Islam. Berbagai warna Islam-dari Aceh, Melayu, Jawa, Sunda, Sasak, Bugis, dan lainnya-riuh rendah memberi corak tertentu keragaman, yang akibatnya dapat berwajah ambigu. Ambiguitas atau juga disebut ambivalensi adalah fungsi agama yang sudah diterima secara umum dari sudut pandang sosiologis. ${ }^{21}$

Berbicara tentang pengaruh budaya dan adat lokal dalam kaitannya dengan agama, tak dapat dipungkiri ada pergulatan dalam upaya mendialogkan antara pesan religiusitas dengan muatan lokal. Perjumpaan agama dengan budaya lokal itu mengambil banyak bentuk. Pertama, mengalami benturan [clash] yang sampai pada titik di mana budaya setempat dihabisi dan diganti yang baru dengan islamisasi misalnya, seperti yang terjadi di Padang tempo dulu. Kedua, ada yang mengambil jalan akomodasi. Artinya, ada pertemuan saling mengisi dan tidak saling menjatuhkan. Islam diterima tapi sebatas simboliknya. Adapun substansi seperti kepercayaan terhadap leluhur tetap lestari. Ketiga, mengambil bentuk hibriditas. Artinya menerima agama tapi separohnya saja, sisanya tradisi setempat. Bentuk ini kemudian biasa dikenal dengan misalnya, Islam Jawa, Islam Banjar, Islam Sasak dan sebagainya. ${ }^{22}$ Dengan demikian, upaya reideologisasi dan retradisionalisasi Islam Nusantara memiliki pijakan yang kokoh baik dari sisi doktrinal, historis maupun budaya.

\section{Pribumisasi Islam Dalam Lanskap Islam} Nusantara

Sejak awal kelahirannya, Islam tumbuh dan berkembang dalam suatu kondisi yang tidak hampa budaya. Realitas kehidupan ini diakui atau tidak memiliki peran yang cukup signifikan dalam mengantarkan Islam menuju perkembangannya yang aktual sehingga sampai pada suatu peradaban yang mewakili dan diakui oleh masyarakat dunia.

Aktualisasi Islam dalam lintasan sejarah telah menjadikan Islam tidak dapat dilepaskan dari aspek lokalitas, mulai dari budaya Arab, Persi, Turki, India sampai Melayu. Masing-masing dengan karakteristiknya sendiri, tapi sekaligus mencerminkan nilai-nilai ketauhidan sebagai suatu unity sebagai benang merah yang mengikat secara kokoh satu sama lain. Islam sejarah yang beragam tapi satu ini merupakan penerjemahan Islam universal ke dalam realitas kehidupan umat manusia.

Gagasan Islam pribumi dalam istilah penulis, Islam Nusantara-secara genealogis, diilhami oleh gagasan pribumisasi Islam yang pernah dilontarkan oleh Abdurrahman Wahid pada paruh akhir tahun 80 -an. Dalam "pribumisasi Islam", tergambar bagaimana Islam sebagai sebuah ajaran yang normatif berasal dari Tuhan yang diakomodasikan ke dalam ruang budaya 
yang berasal dari manusia tanpa kehilangan identitasnya masing-masing. Pribumisasi bukan sebagai upaya menghindari timbulnya perlawanan dari kekuatan-kekuatan budaya setempat, akan tetapi justru agar budaya itu tidak hilang. Karena itu, inti pribumisasi Islam adalah bukan untuk melakukan polarisasi antara agama dan budaya, sebab polariasi demikian memang tidak terhindarkan. ${ }^{23}$

Pribumisasi Islam ini, sejatinya mengambil semangat yang diajarkan oleh Walisongo dalam dakwahnya ke wilayah Nusantara sekitar abad ke-15 dan ke-16 di pulau Jawa. Dalam konteks ini Walisongo telah berhasil memasukkan nilai-nilai lokal dalam Islam yang khas Indonesia. Kreativitas ini melahirkan gugusan baru bagi nalar Islam Indonesia yang tidak harfiah dan tekstual meniru Islam di Arab. Tidak ada nalar Arabisasi yang melekat dalam penyebaran Islam awal di Nusantara. Hal ini tentu saja berbeda dengan apa yang telah dilakukan pada masa selanjutnya, yakni abad ke-17 oleh Abdurrauf al-Sinkili dan Muhammad Yusuf al-Makasari yang lebih bercorak purifikasi dalam pembaruan Islam.

Walisongo justru mengakomodasikan Islam sebagai ajaran agama yang mengalami historisasi dengan kebudayaan. Misalnya, apa yang dilakukan oleh Sunan Bonang dengan mengubah gamelan Jawa yang saat itu kental dengan estetika Hindu menjadi bernuansa zikir yang mendorong kecintaan pada kehidupan transendental. Tembang "tombo Ati" adalah salah satu karyanya. Lebih jauh dalam pentas pewayangan, Sunan Bonang mengubah lakon dan memasukkan tafsir-tafsir bernuansa Islam.

Oleh karenanya, 'Islam Pribumi' sebagai jawaban dari Islam otentik mengandaikan tiga hal. Pertama, 'Islam Pribumi' memiliki sifat kontekstual, yakni Islam dipahami sebagai ajaran yang terkait dengan konteks zaman dan tempat. Perubahan waktu dan perbedaan wilayah menjadi kunci untuk menginterpretasikan ajaran. Dengan demikian, Islam akan mengalami perubahan dan dinamika dalam merespons perubahan zaman. Kedua, 'Islam Pribumi' bersifat progresif, yakni kemajuan zaman bukan dipahami sebagai ancaman terhadap penyimpangan terhadap ajaran dasar agama (Islam), tetapi dilihat sebagai pemicu untuk melakukan respons kreatif secara intens. Ketiga, 'Islam Pribumi' memiliki karakter membebaskan. Dalam pengertian, Islam menjadi ajaran yang dapat menjawab problem-problem kemanusiaan secara universal tanpa melihat perbedaan agama dan etnik. Dengan demikian, Islam tidak kaku dan rigid dalam menghadapi realitas sosial masyarakat yang selalu berubah. Artinya, Islam Pribumi dengan Islam mempunyai kesamaan secara tipologi bukan seperti madzhab.

Konsep yang demikian, Azyumardi Azra menganggap bahwa 
Islam Nusantara seperti diwakili oleh NU dan ormas-ormas washatiyyah yang lain memiliki hampir seluruh potensi untuk tampil dalam mewujudkan peradaban yang rahmatan lil alamin. Modal besarnya adalah kekayaan dan keragaman lembaga mulai dari masjid, sekolah, madrasah, pesantren, perguruan tinggi, rumah sakit dan klinik, panti penyantunan sosial, koperasi, hingga usaha ekonomi lain.

Sehingga banyak kalangan asing sejak akhir 1980-an, semisal Fazlur Rahman memandang potensi besar Islam Nusantara untuk berdiri terdepan dalam memajukan peradaban Islam global. Dengan peradaban Islam wasathiyah (jalan tengah) Islam Nusantara dapat memberikan kontribusi peradaban dunia lebih damai dan harmonis. Harapan seperti ini, menurut Azyumardi Azra, kian meningkat di tengah berlanjutnya konflik di negara-negara Muslim dunia Arab, Asia Selatan, Asia Barat dan Afrika. Untuk itu, NU dan ormas-ormas Islam wasathiyah lain, tidak hanya perlu meningkatkan pemikiran dan amal usaha di dalam negeri, tetapi juga harus lebih ekspansif menyebarkan Islam wasathiyah ke manca-negara. Dengan begitu, Islam Nusantara dapat berdiri paling depan dalam mewujudkan Islam sebagai rahmatan lil alamin. ${ }^{24}$

\section{Kesimpulan}

Islam Nusantara bukanlah suatu bentuk pengkotak-kotakan ataupun sebuah gerakan untuk mengubah doktrin
Islam. Ia juga bukan hendak memindah kiblat umat Islam Indonesia dari Mekkah ke Indonesia. Ia hanya ingin mencari cara bagaimana melabuhkan Islam dalam konteks budaya masyarakat yang beragam. Islam Nusantara hanya ingin menyemai dan menampilkan wajah Islam yang teduh dan ramah bukan marah.

Dengan melihat serpihan-sepihan sejarah yang cukup panjang, Islam (di) Nusantara telah mengalami pergumulan dengan lokalitas yang beragam. Ia hadir bukan untuk mendobrak atau membabat habis tradisi dan budaya lokal yang ada, melainkan coba untuk berdialektika dengan konteks di mana ia berada. Oleh karena sifat fleksibelnya itu, ia mampu bertahan dan berkembang sehingga memunculkan ekspresi keislaman baru yang khas dan tidak ada di belahan dunia manapun.

Akhirnya, hasil kajian, dapat disimpulkan bahwa kemampuan dakwah Islam untuk beradaptasi dengan budaya setempat, memudahkan dakwah Islam masuk ke lapisan paling bawah dari masyarakat. Tak pelak lagi, Islam sebagai agama yang menyebar ke seluruh penjuru dunia tampil secara kreatif berdialog dengan masyarakat setempat (lokal), berada dalam posisi yang menerima tradisi masyarakat, sekaligus memodifikasinya menjadi budaya baru yang dapat diterima oleh masyarakat setempat dan masih berada di dalam jalur Islam. Karena itu, kedatangan dakwah 
Islam merupakan pencerahan bagi kawasan Asia Tenggara, khususnya Indonesia.

\section{Daftar Pustaka}

Abdullah, Taufik. "Pengantar: Islam, Sejarah dan Masyarakat", dalam Taufik Abdullah [ed.], Sejarah dan Masyarakat: Lintasan Historis Islam di Indonesia. Jakarta: Pustaka Firdaus. 1987.

Ali, Fachry. Agama, Islam dan Pembangunan. Yogyakarta: PLP2M. 1985.

Algadari, Hamid. Dutch Policy Against Islam and Indonesian of Arab Descent in Indonesia. Jakarta: LP3ES. 1994.

Ambary, Hasan Muarif. Menemukan Peradaban; Jejak Arkeologis dan Historis Islam Indonesia. Jakarta: Logos Wacana Ilmu. 2001.

Azra, Azyumardi dan Hudson, Wayne (eds.). Islam beyond Conflict: Indonesian Islam and Western Political Theory. England: Ashgate Publishing Limited. 2008.

Azra, Azyumardi. "Islam Indonesia Berkelanjutan”, dalam Opini Kompas. 3 Agustus 2015.

Arbiyah, Lubis. Pemikiran Muhammadiyah dan Muhammad Abduh:Suatu studi Perbandingan Jakarta: Bulan Bintang. 1993.

Baso, Ahmad. Plesetan Lokalitas: Politik Pribumisasi Islam. Jakarta: Desantara. 2002.

Islam Nusantara Ijtihad Jenius dan Ijma' Ulama Indonesia, Jilid I, Jakarta: Pustaka Afid. 2015.
Bresnan, John. Indonesia: The Great Tradition. Maryland, Roman and Littlefield Publishers, Inc. 2005.

Braswell, George W. Islam: Its Prophet, Peoples, Politics and Power. Nashville: Broadman \& Holman Publishers. 1996.

Cornell, Vincent J. (ed.). Voices of Islam, Vol. 5. London: Praeger Publisher. 2007.

Fealy, Greg (eds.). Tradisionalisme Radikal: Persinggungan Nahdlatul UlamaNegara. Terj.

Fasya, Teuku Kemal. “Dimensi Puitis dan Kultural Islam Nusantara", dalam Opini Kompas. 4 Agustus 2015.

Fuad, A. Jauhar, "Tlatah Dan Tradisi Keagamaan Islam Mataraman," Jurnal Pemikiran Keislaman 30, no. 1 (January 31, 2019): 1-27, https://doi.org/10.33367/tribakti. v30i1.659

Geertz, Hildred. "Indonesian Cultures and Communities," in Indonesia, Ruth T. McVey (ed.). New Haven, CT: Human Relations Area Files. 1963.

Geerrtz, Clifford. The Interpretation of Cultures.New York: Basic Books. 1973. Hanson, F. Allan, Meaning in Culture. London and New York: Routledge. 2004.

Iyubenu, Edi AH. "Ontran-Ontran Islam Nusantara", dalam Opini Jawa Pos. 24 Juli 2015.

Maula, Jadul. "Syariat [Kebudayaan] Islam: Lokalitas dan Universalitas", makalah Islam Transformatif dan Toleran. Yogyakarta: LkiS. 2002.

Munandar, Agus Aris. “Kegiatan Keagamaan di Pawitra Gunung Suci di Jawa Timur Abad 14-15", Tesis, Magister Humaniora 
Fakultas Sastra Universitas Indonesia. 1990.

Parkin, Harry. Batak Fruit of Hindu Thought. India: Christian Literature Societ., 1978.

Poespowardojo, Soerjanto. "Pengertian Local Genius dan Relevansinya dalam Modernisasi" dalam Kepribadian Budaya Bangsa (local genius), Ayotrohaedi (ed.). Jakarta: Pustaka Jaya. 1986.

Prayitno, Arohman dan Rahardiansyah P., Trubus. Ethics for a Multicultural Society: Strategic Solutions for Interweaving Togetherness the Frame Work of Pluralism. Jakarta: Trisakti University Press. 2008.

Renard, John. Tales of God's Friends: Islamic Hagiography in Translation. California: University of California Press. 2009.

Sahal, Akhmad (eds.). Islam Nusantara Dari Ushul Figh hingga Paham Kebangsaan. Bandung: Mizan Pustaka. 2015.

Siroj, Said Aqil. Islam Sumber Inspirasi Budaya Nusantara Menuju Masyarakat Mutamaddin. Jakarta Pusat: LTN NU. 2015.

Suaedy, Ahmad. Yogyakarta: LkiS. 1997.

Sunyoto, Agus. Walisongo: Rekonstruksi Sejarah yang Disingkirkan. Jakarta: Transpustaka. 2011.

Tibbi, Bassas. Islam and Cultutral Accommodation of Social Change. San Francisco: Westview Press. 1991.

Utama, Edy. "Adat Basandi Syarak, Syarak Basandi Kitabullah", dalam Ahmad Baso, Plesetan Lokalitas: Politik Pribumisasi Islam.Jakarta:
Wahid, Abdurrahman. Pergulatan Negara, Agama, dan Kebudayaan. Jakarta: Desantara. 2001.

-Islam Kosmopolitan: Nilai-Nilai Indonesia dan Transformasi Kebudayaan. Jakarta: The Wahid Institute. 2007

Walsh, Mary-Paula. Feminism and Christian Tradition: An Annotated Bibliography and Critical Introduction to the Literature. London, Greenwood Press. 1999.

Zada, Khamami. "Islam Pribumi: Mencari Wajah Islam Indonesia", dalam Tashwirul Afkar, jurnal Refleksi Pemikiran Keagamaan \& Kebudayaan, Edisi No. 14 tahun 2003.

Zuhdi, Muhammad Harfin. Parokialitas Adat terhadap Pola Keberagamaan Komunitas Islam Wetu Telu di Bayan Lombok.Jakarta: Lemlit UIN Jakarta. 2009. 